\title{
Notas sobre o retorno às aulas na rede estadual de ensino de Minas Gerais
}

Jakes Paulo Felix Santos $^{1}$, Marlene Teresinha de Muno Colesanti ${ }^{2}$

\section{Resumo}

O presente artigo é resultado de uma revisão bibliográfica dos protocolos sanitários de retorno às aulas para o ano de 2021, concomitante à análise das medidas de aprendizagem propostas no contexto ainda de pandemia. Neste breve exame, apontaremos a exclusão dos professores e dos demais profissionais de educação do papel central que lhes cabe no processo de ensino e de aprendizagem, pari passu suas necessidades no contexto de pandemia. Outrossim, debateremos a necessidade e o verdadeiro lugar da escola como equipamento de inclusão, que é de primordial importância para a construção do tão propalado projeto de vida dos alunos.

\section{Palavras-chave}

Educação. Pandemia. Covid-19. Volta às aulas. Minas Gerais.

\footnotetext{
${ }^{1}$ Mestrando em Geografia na Universidade Federal de Uberlândia, Minas Gerais, Brasil; professor da Rede Estadual de Educação de Minas Gerais, Brasil. E-mail: jakespaulo@gmail.com.

${ }^{2}$ Doutora em Geografia pela Universidade Estadual Paulista Júlio de Mesquita Filho, São Paulo, Brasil; professora titular do Instituto de Geografia da Universidade Federal de Uberlândia, Minas Gerais, Brasil. Email: mmuno@ hotmail.com.
} 


\title{
Notes about the classes' return in the school system of State of Minas Gerais, Brazil
}

Jakes Paulo Felix Santos ${ }^{3}$, Marlene Teresinha de Muno Colesanti ${ }^{4}$

\begin{abstract}
This article is the result of a literature review of health protocols for the return to school in 2021, concomitant with the analysis of the learning measures proposed in the context of pandemic. In this brief examination, we will point out the exclusion of teachers and other education professionals from the central role that they have in the teaching-learning process pari passu their needs in the pandemic context. Furthermore, we will debate the necessity and the real place of the school as an inclusion equipment of primordial importance for the construction of the so-called life project of the students.
\end{abstract}

\section{Keywords}

Education. Pandemic. Covid-19. Return of classes. State of Minas Gerais.

\footnotetext{
${ }^{3}$ Master degree student in Geography, Federal University of Uberlândia, State of Minas Gerais, Brazil; professor at the State Education Network of Minas Gerais, Brazil. E-mail: jakespaulo@gmail.com.

${ }^{4} \mathrm{PhD}$ in Geography, State University of São Paulo Julio de Mesquita Filho, State of São Paulo, Brazil; professor at the Institute of Geography, Federal University of Uberlândia, State of Minas Gerais, Brazil. E-mail: mmuno@hotmail.com.
} 


\section{Introdução}

É indelével que a pandemia de Covid-19 trouxe à tona uma verdade já quase esquecida em tempos de normalidade: a escola é um espaço inexorável da formação das crianças, dos adolescentes, dos jovens e dos adultos. Ela paralisou a sociedade urbana, industrial e capitalista com forte impacto na economia, na produção, na renda, na ampliação da desigualdade social e, consequentemente, na desigualdade educacional.

Para fins de contextualização, importa saber que a pandemia de Covid-19 teve início na China no final do ano de 2019, e que a proliferação da contaminação e o número crescente de óbitos em virtude do novo coronavírus fizeram com que a Organização Mundial de Saúde (OMS), declarasse, em janeiro de 2020, Emergência de Saúde Pública de Importância Internacional. A declaração reconheceu que a doença representava um risco mundial à medida que novos países registraram casos internos de transmissão do vírus e, consequentemente, de óbitos. Em fevereiro de 2020, em razão da rápida dispersão geográfica do vírus, houve, pela OMS, a declaração de pandemia.

O Brasil resistiu, por meio do poder executivo federal, a reconhecer a gravidade da situação e, dentre as nações em desenvolvimento, foi uma das últimas a tomar providências efetivas para a contenção da transmissão interna do vírus. Foi pela Portaria $n^{\circ}$ 188/2020 que o governo federal anunciou a emergência no âmbito nacional, reconhecendo que a situação demandava o emprego urgente de medidas de prevenção, controle e contenção de riscos, danos e agravos à saúde pública. A tônica passou a ser o distanciamento e o isolamento social, além do uso de máscaras e de álcool em gel como forma de prevenção de contaminação pelo novo coronavírus. Consequentemente, houve a suspensão das aulas nas escolas da educação básica no modelo presencial, dominante, e a elaboração, pelas secretarias de educação, do ensino remoto emergencial.

\section{Do ensino e do trabalho na pandemia}

É preciso clarear que o ensino remoto emergencial não deve ser confundido com educação a distância, e que o regime de teletrabalho, dado aos profissionais da educação, não deve ser confundido com home office.

O ensino remoto emergencial foi, e continua sendo, uma alternativa de ensino e de aprendizagem, com uso de tecnologias de comunicação aplicáveis à educação. Grupos de 
WhatsApp foram criados nas escolas, além de páginas no Facebook, lista de transmissão de emails e transmissão de aulas via TV; e, para os alunos sem acesso a celular, notebook, computadores, dentre outros meios, foi fornecido material impresso. Em suma, o ensino presencial físico precisou ser transposto para os meios digitais.

Na Educação a Distância (EaD), os cursos são preparados para esta finalidade. O acesso dos alunos ocorre por plataformas virtuais interativas, como o Moodle, por exemplo, e a matrícula, como escolha pelo estudante, é voluntária. Os professores titulares contam com apoio tecnológico para gravar aulas e interagir com os alunos e com tutores para promover a devolutiva das atividades desenvolvidas. Os estudantes ainda contam, na EaD, com um Ambiente Virtual de Aprendizagem (AVA), local em que são postados textos, hiperlinks e atividades correlatas ao conteúdo ministrado.

A legislação brasileira trata com clareza essa situação por meio do Decreto $\mathrm{n}^{\circ}$ 9.057, de 25 de maio de 2017, que regulamenta o art. 80 da Lei $n^{\circ}$ 9.394, de 20 de dezembro de 1996, o qual estabelece as diretrizes e bases da educação nacional. O decreto afirma que

considera-se educação a distância a modalidade educacional na qual a mediação didático-pedagógica nos processos de ensino e aprendizagem ocorra com a utilização de meios e tecnologias de informação e comunicação, com pessoal qualificado, com políticas de acesso, com acompanhamento e avaliação compatíveis, entre outros, e desenvolva atividades educativas por estudantes e profissionais da educação que estejam em lugares e tempos diversos (BRASIL, 2017).

Pela própria definição, entendemos que o ensino nas escolas de educação básica durante a pandemia do coronavírus nunca foi uma forma de EAD, mas sim de ensino remoto emergencial.

É notório que, embora em outros países do mundo já houvesse suspensão das atividades escolares, o Brasil demorou a ter um plano educacional para enfrentamento da pandemia e, pelos sinais, continua a não o ter.

No que se refere ao teletrabalho, pela sua própria definição, esse, exige algum tipo de tecnologia, o que não é, necessariamente, o caso do home office. Considerando do artigo 75-B da Lei $n^{\circ}$ 13.467/17 da Consolidação das Leis do Trabalho (CLT), pode-se afirmar que a modalidade mais utilizada, no referido contexto, foi o teletrabalho, definida pela legislação como

a prestação de serviços preponderantemente fora das dependências do empregador, com a utilização de tecnologias de informação e de 
comunicação que, por sua natureza, não se constituam como trabalho externo.

Parágrafo único. O comparecimento às dependências do empregador para a realização de atividades específicas que exijam a presença do empregado no estabelecimento não descaracteriza o regime de teletrabalho. (BRASIL, 2017).

Foi considerando esse parâmetro que os profissionais da educação se embrenharam no teletrabalho, muitos comparecendo às escolas para buscar o material impresso devolvido pelos alunos para a correção e validação. Além disso, a maioria dos profissionais da educação esteve disponível para atendimento aos alunos no seu horário de aulas, previamente fornecido pela direção escolar.

O conceito de home office pode parecer não fugir do conceito de teletrabalho, mas o home office pode ser executado sem o uso de tecnologia, enquanto que o teletrabalho pressupõe o uso de ao menos uma delas, sendo que tais atividades se dão exclusivamente fora do local de emprego do trabalhador.

É certo que esse debate, no campo jurídico, ainda é incipiente, mas que com a pandemia tende a ganhar força e, provavelmente, ordenamento legal. Isso até foi tentado por meio da Medida Provisória (MP) n 927/2020, da Presidência da República, cujo prazo para a votação expirou.

Ao que tudo indica, neste primeiro momento do retorno às aulas em 2021, o ensino remoto emergencial e o teletrabalho devem ser a opção a ser seguida pela maior parte das secretarias de educação, considerando que a pandemia de Covid-19 recrudesceu.

\section{Para além da legislação, a realidade}

Após a Segunda Guerra Mundial (1939-1945), o mundo ainda não havia passado por uma situação como foi com a crise, sem precedentes, causada pelo novo coronavírus. Uma das medidas de contenção da proliferação, e também forma de diminuir a pressão sobre o sistema de saúde, foi o fechamento das escolas e a paralisação do ano letivo.

A retomada do ensino de forma remota emergencial foi debatida pelo Conselho Nacional de Educação (CNE), e referendada pelo Parecer $n^{\circ} 5 / 2020$, que prevê a reorganização do calendário escolar e a possibilidade de cômputo de atividades não presenciais para fins de cumprimento da carga horária mínima anual, em razão da pandemia de Covid-19. O referido parecer adverte sobre as consequências de um longo período de interrupção das atividades escolares, cuja suspensão prolongada pode acarretar: 
- dificuldade para reposição de forma presencial da integralidade das aulas suspensas ao final do período de emergência, com o comprometimento ainda do calendário escolar de 2021 e, eventualmente, também de 2022;

- retrocessos do processo educacional e da aprendizagem aos estudantes submetidos a um longo período sem atividades educacionais regulares, tendo em vista a indefinição do tempo de isolamento;

- danos estruturais e sociais para estudantes e famílias de baixa renda, como stress familiar e aumento da violência doméstica para as famílias, de modo geral; e

- abandono e aumento da evasão escolar. (BRASIL, 2020, p. 3.).

Cabe assinalar que essas dificuldades, correlatas à educação nacional, não nasceram com a pandemia, apenas se tornaram mais evidentes, com a possibilidade de se agravarem ainda mais, caso não haja, de fato, um pacto pela educação e pela aprendizagem. Não é de hoje que os indicadores utilizados pelo MEC como mensuradores da evolução da aprendizagem "patinam" ou mostram pouca evolução.

$\mathrm{O}$ acesso desigual dos estudantes aos meios digitais e às redes de internet também são desafios escancarados na pandemia, e mostram a distância entre os mais ricos e os mais pobres para ter o direito à educação, direito esse garantido durante a pandemia.

Todos esses fatos corroboraram para a elevação do abandono e da evasão escolar, previstos pelo MEC no Parecer n. 5/2020.

Os pormenores da evasão e do abandono escolar, no advento da pandemia, ainda carecem de estudos precisos. Mas é certo que, além da responsabilidade do Estado e de seus agentes, mesmo no ensino presencial, anterior à pandemia, os responsáveis pelos estudantes precisam cumprir a sua parte no pacto educativo.

A Constituição Federal de 1988 afirma, no Art. 208, que “compete ao Poder Público recensear os educandos no ensino fundamental, fazer-lhes a chamada e zelar, junto aos pais ou responsáveis, pela frequência à escola" (BRASIL, 2010). Ao mesmo tempo, o CNE debateu essas questões, em especial o acesso e a permanência dos alunos na escola em tempos de pandemia, em virtude do acesso restrito ou inexistente ao ensino remoto emergencial. Assim, a elaboração do já citado Parecer n 5/2020 mostrou que as ações para evitar o abandono e a evasão devem ter início muito antes da reabertura das escolas. O parecer contém as diretrizes nacionais para a implementação dos dispositivos da Lei $\mathrm{n}^{\circ} 14.040$, de 18 de agosto de 2020, que estabelece normas educacionais excepcionais a serem adotadas durante o estado de calamidade pública reconhecido pelo Decreto Legislativo n. 6, de 20 de março de 2020. O parecer se debruça sobre a aprendizagem, a avaliação e o abandono. Ele instrui as 
redes de ensino e os profissionais da educação sobre como proceder para evitar danos, já por anos ignorados pelos sistemas de ensino.

O caos da paralisação do ano letivo é um reflexo da atual situação socioeconômica do país.

A pesquisa "Desafios das Secretarias Municipais de Educação na oferta de atividades educacionais não presenciais", Dirigentes Municipais de Educação (Undime) e do Conselho Nacional de Secretários de Educação (Consed), com apoio do CIEB, Fundação Itaú de Educação e Cultura, revelou que:

- $83 \%$ dos alunos das redes públicas do Brasil vivem em famílias vulneráveis (que recebem até 1 salário mínimo per capita);

- $79 \%$ dos alunos das redes públicas do Brasil tem acesso à internet, mas $46 \%$ acessam apenas por celular;

- $60 \%$ das redes municipais brasileiras determinaram suspensão das aulas com atividades remotas;

- $43 \%$ das que adotam ensino remoto têm optado por usar materiais impressos como parte das estratégias;

- $40 \%$ das redes municipais ainda não têm definições sobre o ensino remoto e $90 \%$ dessas redes são de cidades pequenas (UNDIME, 2020).

Os números são de constranger qualquer dirigente de ensino. Não há como pensar em resolver a situação educacional brasileira, com ou sem pandemia, sem resolver o descompasso social que assola a sociedade.

O ensino remoto emergencial se tornou um desafio também histórico e sociológico, que deve servir para apontar caminhos para a saída da crise educacional, sendo também uma oportunidade de reflexão e de guinada positiva para o futuro.

Os sistemas de ensino precisam, de forma justa e sincera, averiguar o que deu e o que não deu certo no ensino remoto emergencial para, ao se avaliar criticamente, construir as pontes necessárias para uma aprendizagem verdadeira e que minimize prejuízos na aprendizagem dos estudantes. Para tanto, deve-se começar pelas demandas dos discentes, dos docentes e das escolas. Os professores, especialistas e diretores escolares, bem como os

\footnotetext{
${ }^{5}$ O objetivo da pesquisa, dentre outros, foi avaliar as condições da educação municipal na realização de atividades não presenciais e a determinação dos governos em relação à pandemia. Descobrir o perfil das famílias, as estratégias de aprendizagem adotadas, o planejamento para monitoramento das atividades e os principais desafios de implementação do ensino não presencial, foram alguns dos assuntos pautados pela pesquisa "Desafios das Secretarias de Educação do Brasil na oferta de atividades educacionais não presenciais", realizada pelo Conselho Nacional de Secretários de Educação (Consed) e pela União Nacional dos dirigentes Municipais de Educação (Udime), com apoio do Centro de Inovação para a Educação Brasileira (Cieb), Fundação Itaú Social, Fundação Lemann e Fundo das Nações Unidas para a Infância (Unicef). Disponível em: https://undime.org.br/uploads/documentos/php7UsIEg_5ee8efcba8c7e.pdf.
} 
demais profissionais da educação precisam ser ouvidos, assim como os estudantes. As opiniões "das juventudes" precisam ser consideradas ao se propor um novo tempo no ensino.

Se no ensino presencial já existiam problemas como acesso, permanência e sucesso, estes se agravaram na pandemia e carecem de uma avaliação pormenorizada para subsidiar as ações escolares. Nesse caminho, muito se tem falado em ensino híbrido, que vamos considerar aqui como sendo a união simétrica e assimétrica do ensino presencial com o ensino remoto. Não adianta pensar que a prática de abrir laboratórios de informática ou distribuir tablets, computadores e notebooks, ou de transmitir aulas via satélite, ou por televisão, simultaneamente à presença dos estudantes na escola, há de resolver a questão da aprendizagem.

Para o MEC, o hibridismo consiste em

incluir métodos e práticas de ensino-aprendizagem que incorporem o uso integrado de Tecnologias de Informação e Comunicação - TIC para a realização dos objetivos pedagógicos, material didático específico bem como, para a mediação de docentes, tutores e profissionais da educação com formação e qualificação em nível compatível com o previsto no PPC (Projeto Pedagógico do Curso) e no plano de ensino da disciplina. O PPC deverá detalhar a forma de integralização da carga horária das disciplinas ofertadas parcial ou integralmente a distância, e o plano de ensino da disciplina deverá descrever as atividades realizadas. (BRASIL, 2019).

Embora as orientações sejam direcionadas para o Ensino Superior, elas se estendem, por aplicação, à Educação Básica. As escolas foram orientadas pelos dirigentes de ensino a adaptarem seus projetos pedagógicos ao ensino remoto e a toda a legislação correlata.

Essas informações são importantes, mas não debatem a questão na Educação Básica como um todo, tampouco os dados das pesquisas já citadas.

O mundo parou e a educação também. E, de repente, todos se encontraram diante do ensino remoto emergencial, que agora caminha para o hibridismo. Devemos, então, considerar que, no ensino híbrido, o professor possui papel fundamental. É ele quem deve estimular a interação, a colaboração e o envolvimento dos alunos com as tecnologias digitais, à medida que os relaciona com os conteúdos a serem aprendidos, favorecendo esse processo. Devemos, pois, nos debruçar sobre o ensino híbrido.

Moran, Massetto, Behrens afirma que

Híbrido significa misturado, mesclado, blended. A educação sempre foi misturada, híbrida, sempre combinou vários espaços, tempos, atividades, metodologias, públicos. Esse processo, agora, com a mobilidade e a 
conectividade, é muito mais perceptível, amplo e profundo: é um ecossistema mais aberto e criativo. Podemos ensinar e aprender de inúmeras formas, em todos os momentos, em múltiplos espaços. Híbrido é um conceito rico, apropriado e complicado. Tudo pode ser misturado, combinado, e podemos, com os mesmos ingredientes, preparar diversos "pratos", com sabores muito diferentes. (MORAN, MASSETTO, BEHRENS, 2015, p. 22).

Contudo, é preciso que haja o preparo adequado e a compreensão do que é necessário para essa nova etapa da educação nacional. Importa, mais do que nunca, que ela rompa o padrão de exclusão. Não se pode conceber uma educação para um novo tempo que não seja reflexiva: considerar onde se estava antes da pandemia, como foi durante e planejar o pós. É imperioso que haja um plano de ação para todas as ações relacionadas à educação, uma vez que o "ecossistema aberto e criativo" precisa de condições propícias para florescer dentro das escolas.

Já sabemos das dificuldades de acesso dos alunos e dos professores. Sabemos que há professores que não possuem intimidade alguma, ou reduzida, com as tecnologias de informação. Sabemos também que muitos alunos não possuem um acompanhamento adequado do seu percurso escolar e da sua vida acadêmica. Ou seja, muitos dos responsáveis não se envolvem. Não vamos debater aqui os motivos, pois, entre eles, há o amparo preponderante no trabalho como busca do sustento familiar. É polêmico, sabemos. O que importa é como o Estado, em todas as suas esferas, como gestor e mantenedor da educação pública, vai gerir a crise e o pós-crise advindos da pandemia.

\section{Meia volta volver, o retorno das aulas}

Mesmo sem o controle da pandemia, várias entidades do país e outras, de envergadura internacional, defendem o retorno das atividades escolares. Essa defesa tem a oposição da maioria dos sindicatos de trabalhadores em educação, e o debate gira em torno da garantia da saúde dos profissionais envolvidos, que fazem parte do grupo prioritário de vacinação, mas que não ocupam os primeiros lugares na ordem de vacinação, o que se agravou pela inicial lentidão do processo no Brasil, gerando uma disputa que se estendeu até os tribunais.

Dentre os órgãos de defesa ao retorno das aulas está o Fundo das Nações Unidas para a Infância (UNICEF), que elaborou um documento para a América Latina. O documento é de autoria da Seção de Educação do Escritório Regional do Unicef para a América Latina e o 
Caribe, juntamente com as Seções de Saúde e Nutrição; Água, Saneamento e Higiene; Proteção à Infância e Gênero.

Para o Unicef, o retorno às atividades escolares presenciais se baseia no fato de que

Quanto mais tempo as crianças e adolescentes ficarem fora da escola, maior o risco de ficarem atrasados em seu aprendizado, resultando em possíveis impactos negativos a longo prazo sobre o rendimento escolar, a redução da escolaridade e as habilidades cognitivas ao longo de suas vidas. As crianças e adolescentes mais desfavorecidos são os mais prejudicados; aqueles já afetados antes da crise, filhos de pais com níveis de educação mais baixos, entre outros, têm menos possibilidades de voltar à escola. (UNICEF, 2020, p. 8).

O referido documento aponta, então, que existe um abismo educacional entre as crianças e adolescentes na América Latina, em especial entre os mais ricos e os mais pobres, e que a pandemia acentua essas desigualdades. Para o Unicef, os países da América Latina estão em estágios diferentes da pandemia, e a decisão de cada país sobre o retorno deve ser bem avaliada pelos governos. E para orientar os governos latino-americanos, o Unicef lança mão de alguns princípios norteadores, os quais explicamos a seguir.

$\mathrm{O}$ interesse maior da criança e do adolescente, considerando o risco de contaminação de todos os envolvidos no processo de escolarização e o estágio em que se encontra a pandemia de Covid-19. Elaboração de uma abordagem integrada, que contemple equipes compostas por especialistas em educação, nutricionistas, psicopedagogia, para garantir o direito à educação e à proteção mental dos estudantes. É preciso satisfazer o direito à educação de todas as crianças e adolescentes, observando os estágios diferentes de aprendizagem dos alunos. A diversidade que a escola possui deve ser considerada nesse processo. Deve a escola construir sobre as estruturas existentes, o que significa aglutinar associações de pais e mestres, de professores e a comunidade escolar para o aproveitamento das muitas capacidades dessa comunidade. Reafirmar o papel imprescindível dos docentes, que devem ser o elemento-chave na preparação e nos fundamentos da reabertura das escolas, com apoio psicossocial e, ao mesmo tempo, com a valorização da capacidade de cada profissional em promover o acolhimento dos alunos na escola. Ainda é preciso a participação da infância e da juventude como disseminadores de informações corretas e como atores importantes nos processos decisórios que os envolvem no ambiente escolar. Cabe, também, envolver toda a comunidade escolar nesse processo, porque o envolvimento dos pais e responsáveis é particularmente importante para garantir que estes estejam confiantes o suficiente para enviar seus filhos à escola. Para isso, a comunicação deve ser assertiva e a 
decisão compartilhada. Dessa forma, reconstruir a resiliência, para aplicar o que aprendemos com um tempo de isolamento e paralisação das atividades escolares, torna-se uma oportunidade de fortalecer os setores de educação, saúde e proteção, bem como os sistemas de preparação e resposta a desastres, tornando-os mais acessíveis, inclusivos, participativos e protetores.

Importante ressaltar que o Unicef defende que precisa existir um plano de gestão do retorno das atividades escolares com foco na proteção das juventudes e dos profissionais da escola, no sentido de preparar o retorno gradual das atividades escolares conforme o estágio da pandemia. São propostas do Unicef para o retorno gradual:

- Alternância (dias/semanas), entre a aula presencial e a aprendizagem a distância, apoiada em casa;

- Horários escalonados durante o período do dia escolar (horários de início/fim, intervalos, almoço, entre outros);

- Turnos múltiplos ou duplos;

- Redução do número de alunos em sala de aula, e manter os mesmos grupos;

- Priorizar as atividades escolares para que sejam compatíveis com as medidas de distanciamento social. (UNICEF, 2020, p. 13).

Essas propostas são norteadoras para vários órgãos de governo e do terceiro setor que defendem o retorno às aulas, e estão focadas no distanciamento social. Ainda são apresentadas medidas pedagógicas para o retorno das atividades escolares, que ensejam

- Adaptar os calendários acadêmicos;

- Ajustar o tempo de instrução e os horários;

- Simplificar e condensar o currículo com foco nas competências priorizadas durante o resto do ano letivo;

- Ajustar as avaliações ao currículo adaptado;

- Modificar os exames nacionais;

- Flexibilizar e adaptar os requisitos para a progressão escolar;

- Abrir mão de exames menos importantes;

- Aplicar a aprovação universal, onde possível. (UNICEF, 2020, p. 14).

Provavelmente, este seja o gargalo para aqueles que defendem o retorno das atividades: a preparação pedagógica da escola. O desafio de fazer com que todos os alunos sejam contemplados com o ensino e a conquista da equidade educacional e da aprendizagem.

Com base, sobretudo, nas orientações do Unicef, foi que o MEC elaborou um documento intitulado Guia de Implementação de Protocolos de Retorno das Atividades Presenciais nas Escolas de Educação Básica. O documento foi elaborado tendo em vista as orientações da OMS, da Organização Pan-Americana de Saúde (OPAS), da Organização das 
Nações Unidas para a Educação, a Ciência e a Cultura (UNESCO), do UNICEF, além do Ministério da Saúde (BRASIL, 2020). A elaboração também contou com a participação do Consed, da Undime e do Fundo Nacional de Desenvolvimento da Educação (FNDE), no âmbito do Programa Nacional de Alimentação Escolar (PNAE).

Nota-se que as entidades representativas dos estudantes, como a União Nacional dos Estudantes (UNE) e a União Brasileira dos Estudantes Secundaristas (UBES), e dos trabalhadores em educação, como a Confederação Nacional dos Trabalhadores em Educação (CNTE) e a Confederação Nacional dos Trabalhadores em Estabelecimentos de Ensino (CONTEE) não participaram da elaboração do documento. Ficaram de fora, ainda, as entidades pedagógicas de reconhecimento nacional.

O referido Guia reforça que a decisão do retorno às aulas presenciais é exclusiva dos governos municipal e estadual, e traz recomendações pouco divulgadas pelo governo federal, no sentido em que seus pilares são o uso obrigatório de máscaras, a garantia de um distanciamento mínimo de um metro entre os alunos, o uso de equipamentos de proteção individual para os profissionais de ensino e a adoção de regimes de revezamento de equipes, para diminuir a circulação de pessoas.

O MEC avalia a possibilidade de retorno das atividades presenciais no âmbito escolar em virtude da diminuição ou do avanço dos casos de Covid-19. É utilizado um esquema que considera os níveis de intensidade da transmissão da Covid-19, tendo sido associada uma cor a cada um deles para facilitar a compreensão: nenhum caso (azul), transmissão esporádica (verde), transmissão em grupos específicos (amarela) e transmissão comunitária (vermelha). Por essas cores foi elaborado o protocolo do MEC. Mas, a volta às aulas, para o Ministério, segue a premissa da baixa taxa de mortalidade entre as crianças e jovens contaminados pelo novo coronavírus, com base em estudos internacionais e no posicionamento dos organismos internacionais.

O guia do MEC afirma que

Tais estudos indicam que a taxa dos casos registrados no mundo, para a população de crianças e jovens de até 18 anos de idade, gira em torno de $8,5 \%$, com muito poucos óbitos. Os referidos organismos internacionais consideram que, em contraste a esse fenômeno, o fechamento das escolas tem impactos negativos evidentes na saúde física e mental das crianças, assim como na educação, no desenvolvimento, na renda familiar e na economia em geral. (BRASIL, 2020, p. 6). 
Essa inferência do MEC considera ainda estudos do Centro Europeu para Prevenção e Controle de Doenças (ECDC), que afirma que a contaminação em menores de 18 anos não chega a $5 \%$ do total de contaminados pela Covid-19.

Desta forma, considerando o esquema de cores, precisamos entender que os níveis de transmissão no nível local são relevantes para a reabertura das escolas ou para a continuidade das atividades escolares de modo presencial, conforme se observa no quadro a seguir.

Quadro 1 - Situação do nível de transmissão de Covid-19 e considerações para ações da escola

\begin{tabular}{|c|c|}
\hline Nível da Transmissão & Considerações \\
\hline $\begin{array}{c}\text { Azul } \\
\text { (Nenhuma transmissão) }\end{array}$ & $\begin{array}{l}\text { Todas as escolas abertas com medidas de prevenção e controle } \\
\qquad \text { da Covid-19 }\end{array}$ \\
\hline $\begin{array}{c}\text { Verde } \\
\text { (Casos Esporádicos: casos } \\
\text { importados) }\end{array}$ & $\begin{array}{l}\text { Todas as escolas abertas com medidas de prevenção e controle } \\
\qquad \text { da Covid-19 }\end{array}$ \\
\hline $\begin{array}{c}\text { Amarela } \\
\text { (Transmissão local - restrita a } \\
\text { regiões específicas) }\end{array}$ & $\begin{array}{l}\text { A maioria das escolas abrem e implementam medidas de } \\
\text { prevenção e de controle da Covid-19. As autoridades locais } \\
\text { podem fechar as escolas como medida de biossegurança. }\end{array}$ \\
\hline $\begin{array}{c}\text { Vermelha } \\
\text { (Transmissão Comunitária: surto de } \\
\text { transmissão local) }\end{array}$ & Fechamento das escolas \\
\hline
\end{tabular}

Fonte: Elaborada pelo autor com base em documentos do MEC, 2020.

Além de balizar o fluxo por cores de alerta de transmissibilidade da Covid-19, o MEC orienta os gestores locais que façam uma análise da situação dos profisssionais de cada instituição e triagem dos alunos, definindo quem pode ou não retornar. Essa ação deve ocorrer sempre em atuação integrada com profissionais da Unidade Básica de Saúde e/ou Unidades Básicas de Saúde Indígenas, Pólos Base e, no caso de escolas indígenas, das Casas e Apoio a Saúde Indígena (CASAI), separando pessoas do grupo de risco para Covid-19, que são as pessoas com maior índice de mortalidade entre os acometidos pela doença. Para o grupo de pessoas com cardiopatias, doenças pulmonares crônicas, diabetes, obesidade mórbida, doenças imunossupressoras ou oncológicas, pessoas com mais de 60 anos, gestantes e lactantes, devem ser adotadas estratégias de realização de atividades não presenciais.

Para aqueles que estarão aptos a ir para a unidade de ensino, deve ser realizada uma capacitação sobre a doença, sendo providenciados equipamentos de proteção individual (EPI) para esses profissionais. 
Dentre esses EPI, chama a atenção o fato de o MEC indicar a máscara tripla, que garante maior segurança, além de dispensadores de álcool em gel 70\% e de sabonete líquido, embalagens para o descarte das máscaras, limpeza do ambiente com água sanitária e lixeiras que permitam a desinfecção. O MEC também indica que se faça o monitoramento com termômetro (de uso à distância), fitas/adesivos para delimitar o distanciamento recomendado, além de recomendar que se evite o uso de celulares e o compartilhamento de objetos de qualquer tipo. Já no aspecto pedagógico, determina que as diretrizes do CNE sejam as premissas do retorno às salas de aulas.

Pode-se utilizar o ensino híbrido, ou seja, parte dos alunos com aulas presenciais e parte com aulas virtuais e/ou síncronas em casa ou outro local, com atividades e trabalhos a serem realizados em casa. A realização das atividades pedagógicas não presenciais deve possibilitar a efetivação dos direitos de aprendizagem e desenvolvimento previstos na Base Nacional Comum Curricular (BNCC), nos currículos e nas propostas pedagógicas. (MEC, 2020, p. 25).

O ensino por meio de teleaulas, aplicativos, videoaulas e material impresso, e também do uso de grupos de aplicativos de mensagens e aplicativos do Google, foi a tônica do ensino remoto emergencial. Para o ano de 2021, as Secretarias de Estado de Educação do país inteiro planejam o retorno às aulas, ainda que estejamos no momento mais trágico da pandemia no Brasil.

O MEC também recomendou avaliações diagnósticas e formativas para orientar os caminhos, tanto do ensino remoto quanto do ensino a ser implementado em 2021. Pela avaliação diagnóstica, as secretarias de educação e as escolas poderiam planejar as ações de aprendizagem e definir os currículos a serem implementados a cada ano de escolaridade como forma de atrair os alunos e diminuir a evasão escolar.

Vale destacar, ainda, como algumas instituições com tradição na proteção das crianças e dos jovens pensam sobre o retorno às aulas. A maioria delas corrobora com o Unicef, com a OMS e ainda com a Unesco.

Para a Rede Interinstitucional de Educação em Situação de Emergência (INEE) e para a Aliança para Proteção da Criança em Ações Humanitárias (The Alliance),

O fechamento de escolas e períodos prolongados de isolamento em casa podem ter um impacto negativo na saúde mental e no bem-estar das crianças e dos jovens. Crianças e jovens que vivem em ambientes estressantes ou violentos, especialmente as crianças mais jovens, enfrentam distúrbio psicológico, danos físicos e impactos negativos em seu desenvolvimento 
cerebral, devido ao estresse tóxico. As crianças também podem estar enfrentando um risco aumentado de exposição ao trabalho infantil, a todos os tipos de violência e exploração, e (para meninas) ao casamento precoce e à gravidez na adolescência. Em contrapartida, uma educação segura e de qualidade pode oferecer um ambiente de proteção às crianças e aos jovens que correm o risco de serem abusados, explorados e negligenciados. A educação segura e de qualidade permite que as crianças tenham acesso a adultos que podem mantê-las seguras durante o horário escolar e a redes de apoio comunitário que ajudam a protegê-las. A proteção e o bem-estar das crianças devem ser considerações centrais na tomada de decisões sobre o fechamento e a reabertura das escolas. (UNICEF, 2020) ${ }^{6}$.

O foco da INNE é a proteção dos estudantes em situação de vulnerabilidade social e econômica e a importância das escolas na vida social deles. Mas a entidade considera que, na mesma proporção, os educadores também sofrem com a pandemia e com o apressamento do uso de tecnologias de informação para a educação. Para muitos, sem a formação adequada, o uso dessas tecnologias dificulta o ensino e pode frustrar alunos e professores. Ainda assim, o referido documento insiste firmemente na reabertura das escolas com protocolos de segurança claros e apreendidos por todos os membros da comunidade escolar.

Também a Sociedade Brasileira de Pediatria (SBP) opinou sobre a questão do retorno às aulas, afirmando que

\begin{abstract}
Neste momento, uma questão central fundamenta-se na hipótese de que a maioria das escolas, principalmente das redes públicas, não esteja estruturada adequadamente para garantir segurança básica no retorno dos alunos às aulas presenciais. Enfatiza-se o grande problema brasileiro das desigualdades sociais, que neste tema traz novamente o foco para as crianças e adolescentes de classes menos favorecidas, que pagam o maior tributo a esta situação, visto que a maioria das escolas particulares conseguiu avançar no estabelecimento de protocolos sanitários e tecnologia de ensino para seus alunos durante a pandemia. A SBP entende que seu compromisso com a proteção e a saúde de crianças e adolescentes impõe a divulgação dessa nota complementar sobre retorno seguro às escolas. Destaca-se a indispensável responsabilização das autoridades públicas, nas três esferas de governo municipal, estadual e federal, com urgência necessária de planejamento estratégico e investimentos, os quais possam garantir as melhores condições estruturais e de gestão dos processos voltados ao controle de riscos contra a Covid-19 no ambiente escolar, assim como na mobilidade dos alunos pelas cidades. (SBP, 2021, p. 2).
\end{abstract}

A SBP questiona a inércia das autoridades em retomar as aulas, aponta os prejuízos psicológicos, sociais e de aprendizagem e ainda cobra que o Estado planeje e aporte recursos

\footnotetext{
${ }^{6}$ Considerações presentes no documento elaborado pela UNICEF, "medindo o risco: fechamento e reabertura das escolas durante a Covid-19”. Disponível em: https://www.uniceforg/brazil/media/9896/file/nota-alliancevolta-as-aulas.pdf.
} 
que viabilizem o retorno dos estudantes de forma a combater a evasão escolar. O retorno, defendido pela entidade, se baseia em dados de publicações científicas sobre a Covid-19 em menores de 18 anos de idade. Afirma que as crianças e adolescentes representam menos do que $1 \%$ da mortalidade e respondem por $2 \%$ a $3 \%$ do total das internações. A maioria das crianças tem quadro leve ou assintomático. A recomendação e os protocolos de retorno às aulas da SBP são baseados nos documentos do Unicef, da Unesco e da OMS.

\section{Minas Gerais: retorno presencial e hibridismo}

Com o grande número de casos de contaminação da população mineira no início do ano de 2020, as aulas presenciais na rede estadual de ensino de Minas Gerais e nos municípios mineiros foram suspensas.

A suspensão aconteceu por meio da Deliberação $n^{\circ} 1$, de 15 de março de 2020, publicada em 17 de março de 2020, no Diário Oficial do Estado de Minas Gerais (DOEMG), por um prazo de 5 dias consecutivos ou por 3 dias letivos.

Nova deliberação do comitê extraordinário Covid-19, desta vez a nº 15 , de 20 de março de 2020, suspendeu, por tempo indeterminado, as atividades de educação escolar básica em todas as unidades da Rede Pública Estadual de Ensino do Estado, adiantando, inclusive, recessos e feriados.

As duas deliberações anteriores foram revogadas pela Deliberação n. 18, do Comitê Extraordinário COVID-19 MG, de 22 de março de 2020, que estendeu a suspensão ao pessoal do serviço administrativo da educação.

Para o ano de 2021, a Secretaria de Estado de Educação de Minas Gerais (SEE/MG) publicou a resolução $\mathrm{SEE} M G \mathrm{n}^{\circ}$ 4.506/2021, que trata do retorno às aulas de modo híbrido. Contudo, este retorno esteve suspenso por disputas judiciais entre o Estado e o Sindicato Único dos Trabalhadores em Educação de Minas Gerais (Sind-UTE MG), em que o Tribunal de Justiça de Minas Gerais (TJMG) determinou que as aulas retornassem quando os "protocolos sanitários" garantissem a biossegurança dos servidores.

Com decisão favorável ao Governo de Minas Gerais, o TJMG autorizou o retorno gradual e o hibridismo na educação mineira nos termos das Deliberações $n^{\circ} 89$ e $n^{\circ} 129$ do Comitê Extraordinário da Covid-19 e da Resolução SEE MG n 4.506/2021, liberando o retorno das atividades presenciais por meio dos protocolos de biossegurança aplicáveis e disponibilizados pela Secretaria de Educação e de Saúde, deixando a cargo do diretor e do 
inspetor escolar implementar e atestar, através do checklist (previsto no Anexo II da Resolução SEE nº 4.506/21), a implementação de tais medidas.

A luta dos trabalhadores em educação de Minas Gerais também é pela vacinação de todos da categoria, de forma a garantir o retorno seguro às escolas. O Brasil enfrenta um processo lento de produção e de aquisição de vacinas por ausência de políticas afirmativas do Governo Federal, o que pode deixar todo o processo educativo ainda mais prejudicado.

Sobre a forma do retorno às aulas, a SEE/MG (2021) garante que

Dentro do modelo de ensino, o envio e recebimento de atividades escolares para os estudantes deve ocorrer prioritariamente por meios digitais. Para que o estudante tenha acesso ao material Pedagógico - Planos de estudo tutorados, produzido pela SEE ou pelas escolas, por meios físicos - material impresso, é imprescindível que todas as normas e orientações da Organização Mundial da Saúde, do Ministério da Saúde e da Secretaria Estadual de Saúde sejam respeitadas. Quaisquer ações que aumentem o risco de contágio pelo vírus não devem ser adotadas.

Ainda sobre o retorno às aulas, a SEE/MG argumenta que

O retorno presencial, quando autorizado, se dará observando as seguintes premissas: retorno monitorado, consciente, gradual, alternado, seguro, híbrido, facultativo e comunicado. Desse modo, o plano será proposto considerando fases de reabertura, observando os protocolos sanitários de biossegurança, a alternância entre fases de abertura e fechamento das escolas. O retorno presencial à escola será facultativo aos estudantes e famílias que assim o desejarem. Todas as ações de retorno serão amplamente comunicadas à comunidade escolar após a adequação dos espaços escolares para recebimento dos estudantes e profissionais. (SEE/MG 2021).

Superados os entraves judiciais, a SEE/MG ordenou o retorno às aulas para os professores do $1^{\circ}$ ao $5^{\circ}$ ano do Ensino Fundamental no dia 14 de junho de 2021, e dos professores dos anos finais desse nível de ensino a partir do dia 21 daquele mês.

A questão a ser considerada e não esclarecida pela SEE/MG é de como se daria a implantação do programa pedagógico pós pandemia, especialmente no que se refere à aprendizagem dos alunos, ao tempo na escola e aos tempos escolares, bem como à mão-deobra para a execução dos planos pedagógicos ainda não elaborados pela SEE/MG.

A leitura mais simples da Resolução SEE/MG n 4.506/2021 não trata dos aspectos pedagógicos de fortalecimento das aprendizagens dos alunos. A SEE/MG insiste em utilizar avaliações diagnósticas produzidas on-line, sendo que as respostas para tais avaliações estão em várias páginas da internet e continuam a não contemplar os alunos sem acesso aos meios 
digitais, embora garanta que as provas impressas serão entregues aos alunos. A Secretaria tampouco trata de outras modalidades de ensino, como a Educação Integral, Inclusiva e EJA.

\section{Considerações finais}

Não basta apenas que o sistema educacional pense a educação de forma normativa. A escola precisa ser vista como um espaço único e diferenciado. Nenhuma escola é igual à outra.

Num estado de dimensões territoriais e culturais tão grandes como Minas Gerais, a SEE/MG precisa rever a forma de considerar o acesso dos estudantes aos meios de aprendizagem. É preciso um plano pedagógico de fortalecimento das aprendizagens que coloque os alunos como centro do processo e os professores e especialistas em educação como peça chave nesse processo.

Se a SEE/MG não elaborar um plano em que se pense a escola pela escola e não pelos gabinetes, as perdas educativas consequentes da pandemia serão irreparáveis. Serão ainda mais significativas para aqueles alunos que ficaram invisíveis durante a pandemia e que não conseguiram nenhum tipo de acesso à escolarização.

O retorno às aulas precisa ir além da biossegurança das pessoas: é preciso garantir a segurança da aprendizagem e do papel da escola pós pandemia. Sem um plano elaborado com a participação de todos os envolvidos, serão estabelecidas metas vazias e sem forma real para se atingir o sucesso na aprendizagem pelos estudantes.

Somente o retorno seguro para todos, e um projeto educativo elaborado com a participação da sociedade e da comunidade escolar, poderá aglutinar forças necessárias para superar as disparidades educacionais e, ainda, proporcionar aos alunos a elaboração e execução do seu projeto de vida a partir da escola.

Nesse sentido, o Estado deve se imbuir de criar as políticas públicas e o fomento às boas práticas educativas e, ao mesmo tempo, incentivar as medidas sanitárias e a valorização da vida.

\section{Referências}

BRASIL. Ministério da Educação. Guia de implementação de protocolos de retorno das atividades presenciais nas escolas de educação básica. 2020. Disponível em: https://www.gov.br/mec/pt- 
br/assuntos/GuiaderetornodasAtividadesPresenciaisnaEducaoBsica.pdf. Acesso em: 20 fev. 2021.

BRASIL. Ministério da Educação. Parecer CNE/CP n. 5/2020. Reorganização do calendário escolar e da possibilidade de cômputo de atividades não presenciais para fins de cumprimento da carga horária mínima anual, em razão da Pandemia da COVID-19. Brasília: CNE, 2020. Disponível em:

http://portal.mec.gov.br/index.php?option=com_docman\&view=download\&alias=145011pcp005-20\&category_slug=marco-2020-pdf\&Itemid=30192. Acesso em: 14 fev. 2021.

BRASIL. Ministério da Educação. Portaria n. 2.117, de 6 de dezembro de 2019. Dispõe sobre a oferta de carga horária na modalidade de Ensino a Distância - EaD em cursos de graduação presenciais ofertados por Instituições de Educação Superior - IES pertencentes ao Sistema Federal de Ensino. Disponível em: https://www.in.gov.br/en/web/dou/-/portaria-n2.117-de-6-de-dezembro-de-2019-232670913. Acesso em: 17 fev. 2020.

BRASIL. Ministério da Saúde. O que é Covid-19. Brasília: Ministério da Saúde, 2020a. Disponível em: https://coronavirus.saude.gov.br/sobre-a-doenca. Acesso em: 14 fev. 2021.

BRASIL. Ministério da Saúde. Portaria no 188, de 3 de fevereiro de 2020. Declara Emergência em Saúde Pública de importância Nacional (ESPIN) em decorrência da Infecção Humana pelo novo Coronavírus (2019-nCoV). Brasília: Diário Oficial da União: seção I, edição 24-A, 2020b. Disponível em: http://www.in.gov.br/en/web/dou/-/portaria-n-188-de-3de-fevereiro-de-2020-241408388. Acesso em: 16 fev. 2021.

BRASIL. Presidência da República. Decreto n 9.057, de 25 de maio de 2017. Regulamenta o art. 80 da Lei n. 9.394, de 20 de dezembro de 1996, que estabelece as diretrizes e bases da educação nacional. Disponível em: http://www.planalto.gov.br/ccivil_03/_ato20152018/2017/decreto/d9057.htm. Acesso em: 16 fev. 2021.

BRASIL. Lei de Diretrizes e Bases da Educação Nacional. Lei nº 9.394, de 20 de dezembro de 1996. Estabelece as diretrizes e bases da educação nacional. Brasília, DF, 1996.

BRASIL. Presidência da República. Lei no 13.467, de 13 de julho de 2017. Altera a Consolidação das Leis do Trabalho (CLT), aprovada pelo Decreto-Lei n. 5.452, de $1^{\circ}$ de maio de 1943, e as Leis n. 6.019, de 3 de janeiro de 1974, 8.036, de 11 de maio de 1990, e 8.212, de 24 de julho de 1991, a fim de adequar a legislação às novas relações de trabalho. Disponível em: http://www.planalto.gov.br/ccivil_03/_ato2015-

2018/2017/lei/L13467.htm\#: :text=LEI\%20N\%C2\%BA\%2013.467\%2C\%20DE\%2013\%20 DE\%20JULHO\%20DE\%202017.\&text=Altera\%20a\%20Consolida\%C3\%A7\%C3\%A3o\%20 das\%20Leis, $\%$ C3\%A0s\%20novas\%20rela\%C3\%A7\%C3\%B5es\%20de\%20trabalho. Acesso em: 16 fev. 2021.

BRASIL. [Constituição (1988)]. Constituição da República Federativa do Brasil. Brasília, DF: Senado Federal, 1988..

CONSED. Ensino remoto. Brasília, 2020. Disponível em: https://consed.info/ensinoremoto/ . Acesso em: 10 jan. 2021. 
MINAS GERAIS. Resolução SEE/MG n 4.506, de 2 de fevereiro de 2021. Institui o ensino híbrido como modelo educacional para o ciclo dos anos letivos de 2020-2021 e revoga dispositivos da Resolução SEE no 4.310, de 17 de abril de 2020 e da Resolução SEE no 4.329, de 15 de maio de 2020. Disponível em:

https://www2.educacao.mg.gov.br/images/documentos/4506-21-r\%20-\%20public.\%2026-0221.pdf. Acesso em: 1 jun. 2021.

MORAN, J. M.; MASSETTO, M. T.; BEHRENS, M. A. Novas tecnologias e mediações pedagógicas. Campinas: Papirus, 2012.

SANTOS, G. Solicitação de informações sobre o retorno às aulas em Minas Gerais. Mensagem recebida de: acessoainformacao@cge.mg.gov.br. Recebida em: 18 mar. 2021.

SOCIEDADE BRASILEIRA DE PEDIATRIA. Nota complementar: retorno seguro nas escolas. 2021. Disponível em: https://www.sbp.com.br/fileadmin/user_upload/22896d-NC__Retorno_Seguro_nas_Escolas.pdf. Acesso em: 20 fev. 2021.

UNICEF. Notas de orientação sobre a reabertura das escolas no contexto da Covid-19 para os ministérios de educação na América Latina e no Caribe. 2020. Disponível em: https://www.unicef.org/brazil/media/10391/file/notas-orientacao-sobre-reabertura-escolascontexto-covid-19-para-ministerios-educacao-na-america-latina-e-no-caribe.pdf. Acesso em: 20 fev. 2021.

UNICEF. Medindo o risco: fechamento e reabertura das escolas durante a Covid-19. Disponível em: https://www.unicef.org/brazil/media/9896/file/nota-alliance-volta-asaulas.pdf. Acesso em: 20 fev. 2021.

Submetido em 16 de junho de 2021. Aprovado em 26 de agosto de 2021. 